\title{
Documentos de arquivo produzidos pela atividade científica: uma análise dos cadernos de laboratório do Instituto Oswaldo Cruz
}

\author{
Archival documents produced by scientific work: an analysis of \\ laboratory notebooks from the Instituto Oswaldo Cruz
}

\section{Paulo Roberto Elian dos Santos ${ }^{i}$ \\ i Pesquisador, Departamento de Arquivo e Documentação/Casa de Oswaldo Cruz/Fiocruz. \\ Rio de Janeiro - RJ - Brasil \\ orcid.org/0000-0003-1045-4375 \\ paulo.elian@fiocruz.br}

\section{Renata Silva Borges ${ }^{i i}$ \\ ii Arquivista, Departamento de Arquivo e Documentação/Casa de Oswaldo Cruz/Fiocruz. Rio de Janeiro - RJ - Brasil \\ orcid.org/0000.0002.2309.1473 \\ renata.borges@fiocruz.br}

\section{Francisco dos Santos Lourenço ${ }^{i i i}$ \\ iii Pesquisador, Departamento de Arquivo e Documentação/Casa de Oswaldo Cruz/Fiocruz. Rio de Janeiro - RJ - Brasil orcid.org/0000-0002-6048-9608 francisco.lourenco@fiocruz.br}

Recebido em 24 abr. 2018. Aprovado em 22 maio 2018.
SANTOS, Paulo Roberto Elian dos; BORGES, Renata Silva; LOURENÇO, Francisco dos Santos. Documentos de arquivo produzidos pela atividade científica: uma análise dos cadernos de laboratório do Instituto Oswaldo Cruz. História, Ciências, Saúde - Manguinhos, Rio de Janeiro, v.26, n.3, jul.set. 2019, p.1013-1025.

Resumo

Analisa o caderno de laboratório, espécie documental produzida a partir dos registros da atividade científica, e seus diferentes tipos, bem como seu uso e seus formatos na pesquisa biomédica. A reflexão se apoia na pesquisa em andamento sobre os documentos dos laboratórios do Instituto Oswaldo Cruz e na relação destes com os conceitos, métodos, técnicas e práticas da arquivologia. A metodologia compreendeu, além de pesquisa bibliográfica, a aplicação de questionário, entrevistas e diagnóstico dos arquivos, nos quais se buscou identificar a gênese documental, as espécies/ tipologias presentes e as práticas de manutenção e uso dos registros provenientes de 15 laboratórios. Discute ainda o caderno aberto de laboratório, formato disseminado no âmbito do debate contemporâneo da ciência aberta.

Palavras-chave: documento de arquivo; caderno de laboratório; Instituto Oswaldo Cruz; arquivo de laboratório; diagnóstico de arquivo.

\section{Abstract \\ This article analyzes the different types of laboratory notebooks, a type of document produced from the records of scientific work, along with their uses and formats in biomedical research. This reflection is based on current research involving documents from laboratories at the Instituto Oswaldo Cruz and their relationship with the concepts, methods, techniques, and practices of archive studies. The methodology includes bibliographic research, a questionnaire, interviews, and archive diagnostics, which were aimed at identifying the originating documentation, the types which are present, and the practices involved in maintaining and using records from 15 laboratories. We also discuss the open lab notebook, a format which has been discussed within the contemporary debate on open science.}

Keywords: archival documents; laboratory notebook; Instituto Oswaldo Cruz; laboratory archive; archive diagnostics. 
A presente nota de pesquisa tem por base os resultados parciais do projeto de pesquisa "As ciências biomédicas e a trajetória do Instituto Oswaldo Cruz: uma análise dos arquivos institucionais e pessoais" (Santos, 2014). ${ }^{1}$ Esses resultados se referem à elaboração de um diagnóstico dos arquivos do instituto, de forma a possibilitar ações voltadas à classificação, à avaliação e à destinação de seus documentos, como também ao levantamento e identificação dos tipos e espécies documentais ${ }^{2}$ oriundos da atividade científica em laboratórios de pesquisa com vistas à produção de um glossário sobre essa temática, importante instrumento para os processos de organização dos arquivos.

A incorporação dos procedimentos arquivísticos à cultura institucional ocorre na Fundação Oswaldo Cruz (Fiocruz) na década de 1990. O Sistema de Gestão de Documentos e Arquivos (Sigda), instituído a partir desse período, contudo, não logrou êxito no alcance do amplo universo dos laboratórios. A abordagem dos arquivos gerados pela atividade científica tem sido uma preocupação mais recente e exige, por sua dimensão e complexidade, um conjunto de decisões de ordem prática que deve estar ancorado na teoria e nos métodos da arquivologia, em diálogo permanente com os cientistas, técnicos e demais profissionais. Nesse sentido, o tratamento desses arquivos deve ocupar lugar na pauta dos estudos e das ações programáticas voltadas à gestão de documentos. Se essas ações ficaram aquém do desejado, os estudos sobre a produção documental da atividade científica resultaram em um conjunto de trabalhos que poderão sustentá-las em uma nova fase. ${ }^{3}$

A etapa do projeto que norteou a realização deste trabalho se desenvolveu entre fevereiro e setembro de 2016, quando foi processada a coleta de dados para a elaboração do diagnóstico dos arquivos de $15^{4}(20,8 \%)$ dos 72 laboratórios que compõem a estrutura organizacional do Instituto Oswaldo Cruz, unidade da Fiocruz dedicada a desenvolvimento tecnológico, investigação, ensino e prestação de serviços especializados nos campos das ciências biomédicas e da saúde pública. A coleta de dados ocorreu por meio de entrevistas com as equipes dos laboratórios e da identificação preliminar dos documentos neles acumulados. O resultado da análise das informações coletadas nessa etapa do projeto deu origem ao Relatório da coleta de dados e diagnóstico dos arquivos dos laboratórios (Santos, 2017). ${ }^{5}$

Os profissionais entrevistados foram os chefes dos laboratórios de pesquisa e, em alguns casos, os responsáveis pelo Sistema de Gestão da Qualidade dos laboratórios. As questões contempladas no roteiro das entrevistas foram distribuídas em três módulos: o primeiro destinado à identificação do laboratório e do entrevistado, bem como informações sobre a composição de suas equipes; o segundo sobre os procedimentos de gestão de documentos; e o terceiro relativo às características do acervo.

A identificação preliminar do acervo foi realizada por meio da mensuração da documentação de cada laboratório, da identificação dos tipos/espécies documentais mais comuns e do conhecimento das condições gerais de arquivamento e manutenção dos espaços de guarda do acervo.

Após o diagnóstico foi possível identificar um vasto universo de documentos produzidos e acumulados pelos laboratórios, entre os quais um tipo documental se destaca pela relação simbiótica com a "ciência de laboratório": o caderno de laboratório. Propusemo-nos assim a analisar o caderno de laboratório como espécie documental e os seus tipos, com o objetivo 
de compreender suas funcionalidades e formatações, sempre em diálogo e consonância com os conceitos da literatura arquivística.

Na ciência contemporânea é crescente o debate sobre dados científicos abertos, cadernos de laboratórios abertos e on-line. Esse fenômeno revela a influência progressiva do uso das tecnologias da informação e comunicação nas formas de produção documental da pesquisa científica, criando novos modelos de registro e desafios aos profissionais da informação, entre os quais os arquivistas, provocados a rever seus sistemas de gestão, preservação e acesso aos documentos.

\section{Os documentos produzidos e acumulados nos laboratórios}

Há mais de uma década, em documento elaborado para subsidiar discussões sobre sua estrutura organizacional, o Instituto Oswaldo Cruz (IOC) definiu o laboratório de pesquisa como sendo a unidade central de produção do conhecimento e inovação, desenvolvendo atividade de pesquisa básica e aplicada, de desenvolvimento tecnológico, de ensino, de serviços de referência e de manutenção de coleções científicas (IOC, 2006). No entendimento dos dirigentes e pesquisadores do instituto, o laboratório é fruto de um longo processo de construção, amadurecimento e agregação de competências científicas, humanas e materiais, entre outras. O laboratório configura-se ainda como uma estrutura organizacional com atribuições executivas nas áreas de planejamento, orçamento, gestão de recursos humanos, cooperação técnica e captação de recursos para o financiamento das pesquisas.

As funções desempenhadas pelos profissionais que atuam nos laboratórios, e relatadas nas entrevistas, foram categorizadas nas seguintes áreas: pesquisa, coleção, ${ }^{6}$ ensino e formação de recursos humanos, divulgação científica, atendimento ambulatorial e gestão. Trata-se, portanto, de uma "célula" organizacional complexa que tem por base a pesquisa, mas a ela se associam outras funções.

Com o intuito de apresentar um panorama da produção documental, destacamos as atividades de pesquisa que geram os seguintes documentos: artigos publicados, teses, cadernos de protocolo, cadernos de gestão, prontuários médicos, relatórios, documento de entrada de amostra no laboratório (caderno de registro), caderno de registro de amostra, formulários, fichas epidemiológicas, procedimentos operacionais padrão (POPs), termo de consentimento de pacientes, solicitação de exames, manuais de equipamentos, controle de qualidade, guias, manuais, notas técnicas, e-mails, fichas, memorandos e projetos.

Ao longo da pesquisa, pudemos verificar as diferentes nomeações atribuídas aos "cadernos de laboratório", tais como: caderno de protocolo; caderno de registro (ou entrada) de amostras; caderno de patologia; caderno de pesquisa; caderno de soro; caderno de pesquisas clínicas; caderno de isolamento; caderno de resultados de testes, entre outras. Essa diversidade de nomeações parece apontar para a existência de tipologias originadas da espécie caderno de laboratório, mas carece de maiores estudos a serem realizados junto aos cientistas e profissionais diretamente envolvidos com as inúmeras atividades que geraram esses documentos.

Apresentamos a seguir alguns dados gerados e utilizados a partir do diagnóstico dos arquivos. 


\section{Considerações sobre o diagnóstico dos arquivos dos laboratórios}

Os responsáveis pela guarda e manutenção dos arquivos do IOC atuam em consonância com as normativas do Sistema de Gestão da Qualidade implementado na maior parte dos laboratórios pesquisados. Essa ação de documentação da Qualidade se constitui em uma importante tarefa do referido sistema e difere da gestão de documentos, ${ }^{7}$ pois foi criada para atender às especificidades decorrentes do credenciamento dos laboratórios. A gestão de documentos corresponde a uma ação mais ampla que, introduzida no ambiente dos laboratórios, englobaria a documentação da Qualidade.

Vale, portanto, destacar o crescimento da presença do Sistema da Qualidade, encontrado em 73\% dos laboratórios. Nestes, a documentação é decorrente das normas que regulamentam o Sistema da Qualidade, e o credenciamento do laboratório ao referido sistema depende da documentação como pré-requisito. Ao mesmo tempo, 40\% dos entrevistados informaram utilizar normativas específicas para criação e manutenção dos cadernos de protocolo e outras atividades de pesquisa ou gerenciais do laboratório, o que evidencia um cenário mais complexo no que se refere a identificação, produção e gestão documental.

Em $60 \%$ dos laboratórios foi possível identificar um profissional responsável pela guarda e manutenção dos documentos de arquivo. No entanto, apenas 33\% declararam ter conhecimento da participação de membros de suas equipes nos eventos e treinamentos ${ }^{8}$ para capacitação nos métodos e técnicas de gestão de documentos oferecidos pela Fiocruz.

Em regra, os profissionais designados pelos chefes dos laboratórios para assumir a responsabilidade pela guarda e manutenção dos arquivos têm conhecimento das atividades de pesquisa e do Sistema da Qualidade, mas não têm conhecimento e prática no tratamento documental apoiado nos métodos e técnicas arquivísticas.

Entre os entrevistados, $73 \%$ concordam que alguns documentos da etapa de desenvolvimento da pesquisa devem ser preservados, sobretudo aqueles que contêm informação sobre o histórico da atividade de pesquisa no laboratório e os documentos de valor histórico, como os cadernos de protocolo, mencionados com destaque em algumas entrevistas.

Os entrevistados, em 94\% dos laboratórios visitados, declararam que possuem documentos eletrônicos em seus computadores de trabalho arquivados em pastas gerenciadas por eles mesmos ou no sistema eletrônico utilizado pela equipe. A esses sistemas de gerenciamento de informações e documentos oriundos da atividade de pesquisa não tivemos acesso.

Somente $73 \%$ mencionaram que possuem documentos com restrição de acesso, entre os citados está o caderno de registro de amostras.

Em síntese, o diagnóstico revela uma ampliação - ainda que tímida - de medidas na gestão dos arquivos. A consolidação do Sistema da Qualidade tende a impor "constrangimentos" às práticas descompromissadas com o registro das atividades e experimentos típicos dos diversos processos constituintes da atividade de pesquisa e desenvolvimento tecnológico nos laboratórios. Nesse ambiente, o caderno de laboratório e seus similares merecem uma identificação arquivística mais criteriosa. 


\section{Caderno de laboratório: documento da ciência}

$\mathrm{O}$ estudo das tipologias documentais pela arquivologia é relativamente recente. $\mathrm{O}$ conhecimento sobre as tipologias se revela crucial para várias etapas do tratamento documental em arquivos (identificação, arranjo, descrição e elaboração de instrumentos de pesquisa), sobretudo para as implicações que a relação entre arranjo e descrição documental têm para a preservação e o acesso aos arquivos. Estudos dessa natureza em arquivos de instituições científicas são ainda mais recentes (Silva, 2014). Na concepção de Ana Maria Camargo (2014), identificar as tipologias é a base do trabalho arquivístico. Elas traduzem os procedimentos mediante os quais a instituição logra cumprir suas finalidades, refletindo rotinas e adequações impostas pela passagem do tempo.

O caderno de laboratório é o traço cotidiano do trabalho científico, uma transcrição das experiências, dos resultados, sem uma ordenação particular. É assim denominado como forma de distingui-lo da caderneta ou caderno de campo, utilizado nas ciências humanas (arqueologia, etnologia, sociologia, antropologia etc.). "As ciências biomédicas também fazem uso dos cadernos de campo, principalmente a ciência vinculada à tradição naturalista dos botânicos, zoologistas e entomologistas" (Santos, Pinto, Santos, 2012, p.168).

A compreensão das funções dos documentos de um arquivo depende do conhecimento sobre o contexto de produção e de uso dos documentos que o compõem. No IOC, a pesquisa, o ensino e a coleção, principais atividades identificadas na coleta de dados, fazem parte de um mesmo contexto no qual se desenvolvem as pesquisas biomédicas. Selecionamos no universo desta pesquisa os cadernos de laboratório, em suas diferentes espécies e formatos, para analisá-los e tentar compreender mais detalhadamente sua gênese, seu contexto de produção e uso.

Na etapa de diagnóstico dos arquivos, o caderno de protocolo, o artigo, POPs, o relatório e o projeto de pesquisa foram os documentos mais citados pelos profissionais. Vale destacar que esses documentos dizem respeito às três fases da pesquisa, a saber: planejamento e administração da pesquisa (projeto); desenvolvimento da pesquisa (POPs e caderno de protocolo); comunicação e disseminação dos resultados (artigo e relatório) (Santos, Pinto, Santos, 2012).

No início dos anos 2000, no âmbito do Programa de Gestão da Qualidade em Pesquisa e Desenvolvimento Tecnológico, a Fiocruz implantou um POP do Livro de Registro. Esse livro, também conhecido como Livro Verde, é uma versão do caderno de protocolo, cujo uso e manutenção passou a ser orientado por padrões atuais da ciência: "O livro é criado, utilizado e arquivado com base em um conjunto de procedimentos absolutamente inerentes aos documentos de arquivo e compatíveis com os parâmetros da ciência contemporânea" (Santos, Pinto, Santos, 2012, p.166). Ainda segundo os mesmos autores, "o caderno de protocolo descreve as rotinas da pesquisa em sua fase de desenvolvimento, serve como testemunho das experiências, dos dados e resultados obtidos" e mantêm relações orgânicas com os demais documentos e com seu contexto de produção (p.171-172).

$\mathrm{Na}$ concepção dos cientistas, esse e outros documentos valem como elementos de prova daquilo que se fez e se faz em um laboratório e, portanto, podem perpetuar uma determinada memória. O valor de guarda identificado pelos mesmos a esse material está 
relacionado ao valor por eles atribuído à sua ciência, ou, quando muito, à ciência do seu grupo ou da sua instituição. Em suma, é possível perceber "nos cientistas uma dificuldade de estabelecer nexos entre o que produzem hoje, o acúmulo do que produziram em suas trajetórias, suas trajetórias e o uso que a sociedade poderá fazer de tudo isso" (Santos, Pinto, Santos, 2012, p.175-176).

A nomeação muito diversa dos cadernos de laboratório e dos documentos similares foi fornecida pelos cientistas entrevistados ao longo da coleta de dados. No Manual para gestão de documentos e arquivos de laboratórios das ciências biomédicas (Santos, 2011), produto de projeto de pesquisa realizado entre 2010 e 2011, a pesquisadora do IOC Elisa Cupollilo atribuiu aos diários e cadernos de protocolo grande importância para suas atividades, pois por meio desses documentos são efetuados os registros escritos do cotidiano da pesquisa:

A atividade de pesquisa sempre teve como princípio o registro das observações, fossem elas em diários, fossem em cadernos particulares dos pesquisadores, mas o fato é a necessidade de se registrar informações frutos de experimentos ou não.

Hoje, essa ferramenta básica são os cadernos de protocolo. Neles são registrados todos os ensaios, as metodologias e os resultados obtidos a partir desses ensaios. Como constituímos esses cadernos de protocolo varia muito, em função das instituições e dos laboratórios. Ou seja: dentro de uma instituição isso pode estar padronizado, ou então você pode dar a liberdade para que cada indivíduo registre as informações. $\mathrm{O}$ fato é que esses cadernos precisam reproduzir os experimentos e os resultados. ... Hoje nós temos muitos registros reunidos em meio digital e mesmo em fichas padronizadas ... que podem ser arquivados de muitas maneiras.

Ao mencionar esses registros, a então chefe do Laboratório de Leishmaniose destaca os cadernos de laboratório como documentos representativos no vasto universo documental produzido pela pesquisa e nos revela a diversidade de situações que trafegam entre dois pontos: da extrema normalização e controle documental à "liberdade" que delega aos pesquisadores as decisões de produção, manutenção e uso dos cadernos.

Ao cotejarmos o Manual para gestão de documentos e arquivos de laboratórios das ciências biomédicas (Santos, 2011) e o Glossário de espécies e tipos documentais em arquivos de laboratório (Silva, 2014), identificamos os termos caderno de campo, caderno de laboratório, caderno de protocolo (ou caderno de registro) e diário.

\section{Caderno de campo}

O caderno de campo é uma espécie documental conhecida também como livro de campo ou caderneta de campo e é utilizado para registrar informações sobre o material oriundo de expedições ou coletas simples. Pode conter, além das informações do próprio material, outras tantas relativas ao ambiente da coleta, como

paisagem das localidades, tipos de biótopos, de formações vegetais, de água ou de solos, clima, observações de cunho ecológico, etiológico. O livro de campo poderá conter: itinerário e datas; paisagem; procedência; localidade; data de coleta; nome(s) do(s) coletor(es); informações de campo; números de campo (Papavero citado em Santos, 2011). 
Segundo o glossário produzido por Silva (2014, p.20), o caderno de campo é "utilizado por pesquisadores de diversas áreas para registrar observações de natureza técnica ou científica durante o trabalho de campo".

\section{Caderno de laboratório}

O caderno de laboratório é definido por Silva (2014, p.21) como espécie documental também conhecida como caderno de bordo, caderno de experimento, logbook, caderno de pesquisa, caderno técnico, caderno pessoal e diário de bordo. Ou seja:

Caderno de dimensões variáveis, utilizado por pesquisadores para registrar hipóteses, experimentos, análises, interpretações e trabalhos conduzidos pelo laboratório. É uma ferramenta onde se registra tudo o que ocorreu no trabalho, incluindo informações rotineiras das atividades, com o objetivo de organização, rastreamento, memória, correções e, ainda, de proteção à propriedade intelectual. Pode ser utilizado em formato eletrônico comumente chamado logbook (Silva, 2014, p.21).

Figura 1: Caderno de laboratório e suas denominações

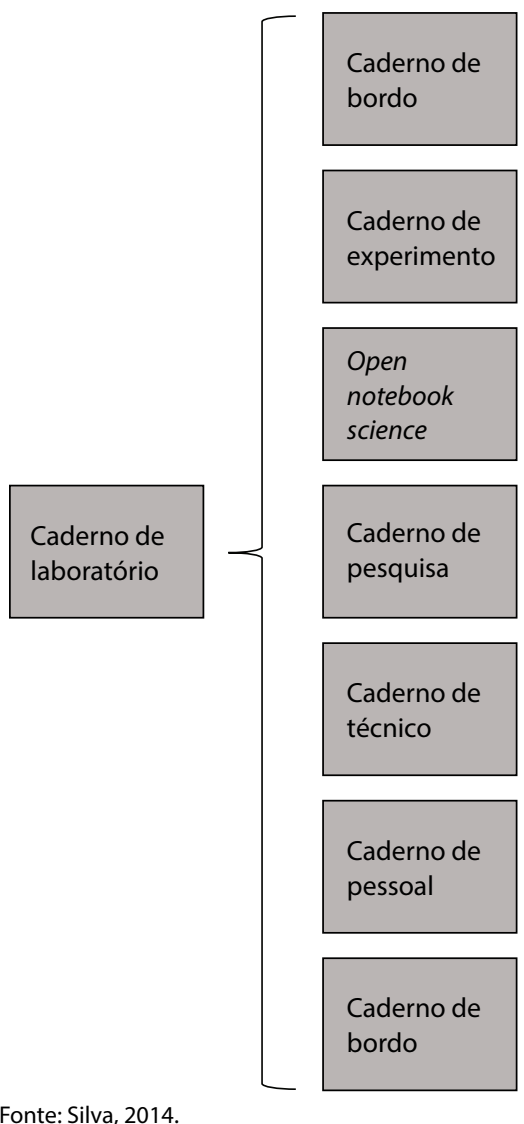

A finalidade do caderno de laboratório é organizar, rastrear, reter memória, proteger a propriedade intelectual etc.

Como substitui o caderno de bordo e outras espécies/tipos, podemos supor que o documento que os pesquisadores chamam de caderno de laboratório é capaz de agregar informações que se sobrepõem e se complementam nas diferentes espécies e tipos documentais que coexistem no universo da atividade científica.

Trataremos do Open notebook science na subseção seguinte, dedicada a uma breve reflexão sobre os documentos digitais. 


\section{Caderno de protocolo (ou caderno de registro)}

O caderno de protocolo, também nomeado caderno de registro de amostra e livro de protocolo, é definido como espécie documental tanto por Santos (2011) quanto por Silva (2014). Para o primeiro autor, ele é o documento que reúne

as anotações brutas das experiências que testemunham a investigação cotidiana do pesquisador no ambiente do laboratório. Possui igualmente um valor probatório em casos de conflitos a propósito de determinada descoberta ou experiências realizadas no processo de pesquisa. De um modo geral não há regra para a criação e uso do caderno. Tudo que é feito e verificado no decorrer da pesquisa deve ser anotado no caderno (Santos, 2011).

Para Silva (2014, p.28), o livro de protocolo é destinado "ao controle das atividades do laboratório, por ordem de chegada, os itens adquiridos, com a atribuição de um número sequencial". Seus tipos são: livro de registro de amostra, livro de registro de análise da amostra, livro de registro de entrega de processo, livro de registro de entrega da amostra e livro de registro de manutenção de equipamento.

\section{Diário}

O diário é uma espécie de caderno onde são anotados diariamente "as principais ocorrências de cada jornada de trabalho tanto nas pesquisas de campo como nas atividades docentes" (Silva, 2014, p.24). Seus tipos mais comuns são: diário de campo, diário de laboratório e diário de pesquisa (Santos, 2011).

Figura 2: Fluxo das atividades dos cientistas e sua relação com espécies e tipos documentais na fase de desenvolvimento da pesquisa

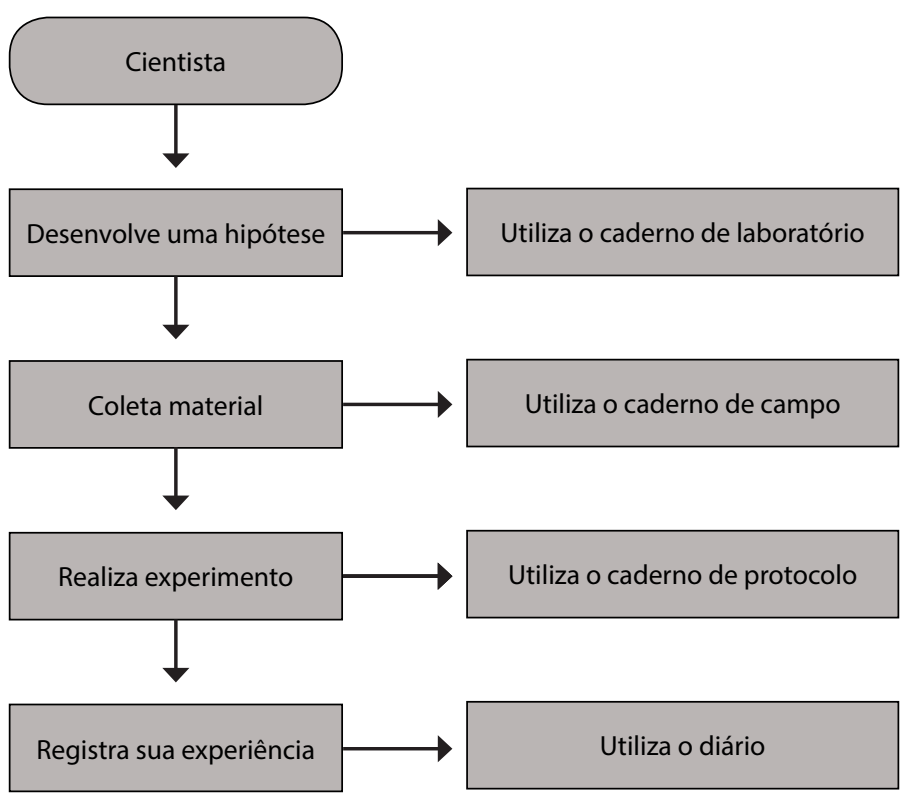

Fontes: Santos, 2010; Silva, 2014. 
Para comparar os resultados de nossa análise dos conceitos e identificar a existência de possíveis discordâncias entre o ponto de vista da arquivística e o dos cientistas que entrevistamos, é necessário aprofundar a pesquisa nos próprios cadernos de laboratório. O objetivo dessa continuidade é ajustar os resultados dos fluxos de produção do caderno de laboratório de acordo com os que eles mantêm arquivados em papel e com os que são gerados eletronicamente. Pretende-se ainda verificar se houve mudanças em relação às funções desses documentos com a utilização da tecnologia digital.

\section{O debate contemporâneo na ciência: documento, acesso e dados abertos}

O debate contemporâneo sobre os registros (dados científicos) ${ }^{9}$ gerados na pesquisa científica e seu acesso envolve o reconhecimento do uso de tecnologias nas diversas atividades de uma instituição de pesquisa. Nos resultados do estudo aqui apresentados, verifica-se que a atividade científica gera diversas espécies e tipologia documentais no seu desenvolvimento. A questão que se coloca nos dias atuais é como o registro da pesquisa científica tem acontecido a partir das Tecnologias da Informação e Comunicação (TICs) e como o uso destas pode ampliar a capacidade de criação, processamento, circulação, difusão e acesso, assim como a possibilidade de colaboração entre pares com o compartilhamento dos dados gerados nesse contexto.

Quando mencionamos o open notebook science na descrição que fizemos dos cadernos de laboratórios, estávamos introduzindo uma versão eletrônica de uma nova questão: em que medida o open notebook science, versão digital dos cadernos de laboratórios, é apenas um novo formato? Ele apresenta possibilidades de mudança nas formas de registro e compartilhamento de informações durante a etapa de desenvolvimento da pesquisa.

A ciência contemporânea já funciona nessa marcha. Trecho da entrevista de um pesquisador do IOC, realizada em 2010, revela a presença do caderno digital ainda como um "desejo" parcialmente materializado, em convivência com o formato físico:

Eu utilizo [caderno de protocolo], até um tempo atrás ele era todo físico, mas pessoalmente eu agora tenho uma espécie de livro eletrônico. Mas aqui no laboratório todos os alunos e pesquisadores mantêm o caderno físico. A ideia era que no futuro a gente pudesse transformar tudo em livro eletrônico. Até existe uma iniciativa já para isso, chamada Eletronic Notebook, que está muito mais voltada para os laboratórios da indústria farmacêutica que exigem um nível de controle muito maior e uma certa fluidez e facilidade na troca de informações. Eu cheguei a avaliar um programa, um esquema de algoritmo para isso, a ideia era em algum momento isso ser institucional. Porque na verdade o caderno de protocolo é um documento ... talvez seja o menos conhecido, mas é o mais importante, porque na hora que se tem uma dúvida sobre um resultado ... [vai recorrer a ele] (Santos, 2011).

De acordo com Anne Clinio (2015), a adoção de um caderno de laboratório em formato digital significa mais do que a migração das informações dos documentos em papel para softwares, dadas as possibilidades de interação entre os agentes na produção de conhecimento científico que conduziriam à agilidade na incorporação de dados, disseminação de informação e produção de cópias (incluindo as de segurança e backups). A autora cita os cadernos 
de laboratório na perspectiva do open notebook science, uma ferramenta capaz de agregar informações da etapa intermediária de forma dinâmica e instável.

As justificativas para a adoção do open notebook science é oferecer os dados brutos do pesquisador registrados no caderno de campo eletrônico na rede aos olhos de qualquer pessoa que se interesse por sua análise, interpretação e utilização (Clinio, 2015). A iniciativa proposta possibilita: conhecimento do que se passa na etapa de desenvolvimento da pesquisa; interação dos atores envolvidos em redes com a finalidade de produzir conhecimento científico; redução ou supressão da exclusividade da autoria na etapa posterior (publicação e disseminação dos resultados); agilidade nos processos de trabalho e rapidez no alcance de resultados visando à imediata aplicabilidade dos resultados; e conhecimento dos experimentos fracassados.

Outro ponto abordado por Clinio sobre o open notebook science se refere aos aspectos econômicos que cercam os financiamentos da atividade científica, que estariam condicionados a maior ou menor transparência e clareza no registro de informações sobre os experimentos.

No entanto, essa proposta apresenta algumas questões de natureza ética. Até que ponto essa proposta de abertura estaria isenta das amarras do mercado liberal ao romper com o viés social, ao privilegiar os incentivos econômicos como fatores motivadores da abertura? Seria possível uma economia política da informação científica e tecnológica dentro de uma lógica liberal? Os dispositivos reguladores em nível local e global protegeriam ou exporiam os agentes envolvidos? Sob a perspectiva institucional, qual é o impacto do uso desses cadernos no desenvolvimento das pesquisas científicas? Como a instituição poderia gerir o conhecimento registrado nesse formato? Como os profissionais da informação podem contribuir na gestão e acesso a esses registros, considerando as normas e legislação vigentes?

Ao refletir sobre uma pseudo open notebook science, a autora ilumina alguns aspectos obscuros da abertura, como: as possibilidades de manipulação do tempo de publicação dos trajetos da pesquisa, bem como dos resultados, sem comprometer a ética nessas relações; a cobrança pelos serviços de acesso às plataformas em diferentes níveis de interação; a regulamentação em nível global, embora seja uma saída, poderia não ser democraticamente distributiva em matéria de direitos e deveres, considerando as diferenças econômicas e sociais do globo.

A noção de open notebook science ainda merece muita reflexão por parte da comunidade científica, incluindo as instituições, os laboratórios de pesquisa das ciências biológicas, e as áreas vinculadas às ciências sociais, como a arquivologia, a ciência da informação e a sociologia, visando à desnaturalização do uso das tecnologias como dispositivo único do progresso das sociedades. Esse progresso não pode prescindir dos avanços tecnológicos desde que eles contribuam para uma reflexão capaz de escapar das armadilhas das polarizações e caminhar no sentido de uma ciência em diálogo permanente com a solução de problemas e o desenvolvimento. 


\section{Considerações finais}

Os laboratórios do IOC contemplados pela pesquisa são ambientes institucionais que comportam atividades complexas em diferentes escalas e produzem volume expressivo de documentos com dados e informações em saúde. A adoção de procedimentos de criação, tramitação, uso e destinação dos documentos encontra-se ainda muito distante do desejado. Nesse ambiente, o caderno de laboratório e suas diferentes nominações (caderno de pesquisa, caderno de protocolo, caderno de registro, diário etc.) é um registro controlado e, em muitos laboratórios, regulado por normas externas que tendem a ser assimiladas pela cultura institucional. A adoção mais ampla do "livro verde" deve ser um objetivo institucional. Contudo, são recomendados novos estudos dedicados exclusivamente a essa tipologia, de forma a incluir sua versão digital interna e/ou aberta. Isto é, o caderno de pesquisa aberto, ou open notebook science, praticado de forma pioneira em projeto voltado à descoberta de medicamentos para a malária, conforme apontam Albagli, Clinio e Raychtock (2014).

Os novos estudos, apoiados em uma abordagem arquivística preocupada em compreender o funcionamento da ciência contemporânea, e na maior interação dos cientistas com os diversos profissionais que tratam da gestão dos documentos e das informações dos laboratórios, poderão apontar para uma renovação das práticas da ciência e do aperfeiçoamento de sua relação com a sociedade.

\section{NOTAS}

${ }^{1}$ O projeto foi contemplado em 2015 no Edital Jovem Cientista/Papes VII/Fiocruz-CNPq. A equipe do projeto, constituída por profissionais do Departamento de Arquivo e Documentação da Casa de Oswaldo Cruz (DAD/COC), atuou em colaboração com os profissionais dos laboratórios do Instituto Oswaldo Cruz (IOC). Agradeço a Elisa Cupollilo, então vice-diretora do IOC, pelo apoio.

${ }^{2}$ Consideramos espécie documental "a configuração que assume um documento de acordo com a sua disposição e a natureza das informações nele contidas" (Camargo, Bellotto, 1996, p.34) e tipo documental "a configuração que assume uma espécie documental de acordo com a atividade que a gerou" (p.74). Ver também Bellotto (2008).

${ }^{3}$ Há mais de uma década o Museu de Astronomia e Ciências Afins (Mast) e a Casa de Oswaldo Cruz/ Fiocruz têm realizado pesquisas que tratam de diferentes aspectos relacionados aos arquivos de instituições científicas e aos arquivos pessoais de cientistas. Destacam-se os estudos sobre produção documental, tipologias e classificação em arquivos pessoais, entre outros. Ver Castro, Lourenço (2009); Santos (2010); Santos, Pinto, Santos (2012); Silva, Santos (2012); Silva, Barboza (2012).

${ }^{4}$ Os laboratórios que participaram do projeto foram: Laboratório de Helmintos Parasitos de Vertebrados, criado na década de 1910; Laboratório de Vírus Respiratório e Sarampo, criado na década de 1950; Laboratório de Enterovírus, criado em 1960; Laboratório de Hanseníase, criado em 1975; Laboratório de Mosquitos Transmissores de Hematozoários, criado em 1979; Laboratório de Pesquisas em Leishmaniose, criado em 1980; Laboratório de Doenças Parasitárias, criado em 1980; Laboratório de Biologia Molecular e Doenças Endêmicas, criado em 1980; Laboratório Interdisciplinar de Vigilância Entomológica em Diptera e Hemiptera, criado em 1983; Laboratório de Inflamação, criado na década de 1980; Laboratório de Aids e Imunologia Molecular, criado em 1991; Laboratório de Patologia, criado em 1991; Laboratório de Biologia Estrutural, criado em 2009; e o Laboratório de Estudos Integrados em Protozoologia, criado em 2015.

${ }^{5}$ Projeto "As ciências biomédicas e a trajetória do Instituto Oswaldo Cruz: uma análise dos arquivos institucionais e pessoais". Relatório da coleta de dados e diagnóstico dos arquivos dos laboratórios. Papes VII Ficruz/CNPq, maio de 2017 (Santos, 2017).

${ }^{6}$ Segundo a definição do "Manual de organização de coleções biológicas da Fiocruz" (2017), coleção biológica é um conjunto de material biológico devidamente tratado, conservado e documentado de acordo com normas e padrões que garantam a segurança, acessibilidade, qualidade, longevidade, integridade e 
interoperabilidade dos dados da coleção, pertencente à instituição de ensino e/ou pesquisa com objetivo de subsidiar atividades de ensino, serviço, pesquisa, desenvolvimento tecnológico, inovação, divulgação científica, além de conservação ex situ. Estas coleções podem ainda apresentar valioso material de importância histórica (Fiocruz, 2017).

${ }^{7}$ Gestão de documentos pode ser definida como o "conjunto de medidas e rotinas visando a racionalização e eficiência na criação, tramitação, classificação, uso primário e avaliação de arquivos" (Camargo, Bellotto, 1996, p.41).

${ }^{8}$ Os eventos e treinamentos são regularmente oferecidos pelo Serviço de Gestão de Documentos do DAD/ COC e pelos profissionais que integram a equipe do Sistema de Gestão de Documentos e Arquivos (Sigda/ Fiocruz).

${ }^{9}$ Registros factuais (resultados numéricos, documentos textuais, imagens e sons) usados como fonte primária para a pesquisa científica e que são comumente aceitos pelos pesquisadores como necessários para validar os resultados do trabalho científico (OECD, 2007, p.13).

\section{REFERÊNCIAS}

ALBAGLI, Sarita; CLINIO, Anne; RAYCHTOCK, Sabryna.

Ciência aberta: correntes interpretativas e tipos de ação. Liinc em Revista, v.10, n.2, p.434-450. 2014.

BELLOTTO, Heloísa Liberalli.

Diplomática e tipologia documental em arquivos. Brasília: Briquet de Lemos. 2008.

CAMARGO, Ana Maria de Almeida. Apresentação. In: Silva, Maria Celina Soares de Mello e (Org.). Glossário de espécie e tipos documentais em arquivos de laboratórios. Rio de Janeiro: Museu de Astronomia e Ciências Afins. p.5. 2014.

CAMARGO, Ana Maria de Almeida; BELLOTTO, Heloísa Liberalli.

Dicionário de terminologia arquivística. São Paulo: Associação dos Arquivistas Brasileiros/Núcleo Regional de São Paulo; Secretaria de Estado da Cultura. 1996.

CASTRO, Maria Conceição; LOURENÇO, Francisco dos Santos.

Tipos documentais e padronização da descrição arquivística: um estudo de caso sobre arquivos científicos. In: Encontro de Arquivos Científicos, 4., 2009, Rio de Janeiro. Anais... Rio de Janeiro: Casa de Rui Barbosa. p.54-62. 2009.

CLINIO, Anne.

Por que open notebook science? Uma aproximação às ideias de Jean-Claude Bradley. In: Albagli, Sarita; Maciel, Maria Lucia; Abdo, Alexandre Hannud (Org.). Ciência aberta, questões abertas. Brasília: Ibict; Rio de Janeiro: Unirio. 2015.

FIOCRUZ.

Fundação Oswaldo Cruz. Manual de organização de coleções biológicas da Fiocruz. Disponível em: <https://portal.fiocruz.br/sites/ portal.fiocruz.br/files/documentos/vppcb-mcb-001_manual_de_organizacao_colecoes_da_ fiocruz_0.pdf>. Acesso em: 20 mar. 2018. 2017.

IOC.

Instituto Oswaldo Cruz. Inovações gerenciais no IOC: avaliação de laboratórios de pesquisa e distribuição orçamentária por produtividade. Rio de Janeiro: Fundação Oswaldo Cruz/ Instituto Oswaldo Cruz. 2006.

OECD.

Organisation for Economic Co-operation and Development. OECD principles and guidelines for access to research data from public funding. Paris: OECD. Disponível em: <http://www.oecd. or/sti/sci-tech/38500813.pdf >. Acesso em: 13 set. 2016. 2007.

SANTOS, Paulo Roberto Elian dos. Relatório da coleta de dados e diagnóstico dos arquivos dos laboratórios. Rio de Janeiro: Fundação Oswaldo Cruz/Casa de Oswaldo Cruz. 2017.

SANTOS, Paulo Roberto Elian dos. As ciências biomédicas e a trajetória do Instituto Oswaldo Cruz: uma análise dos arquivos institucionais e pessoais. Rio de Janeiro: Fundação Oswaldo Cruz/Casa de Oswaldo Cruz. 2014.

SANTOS, Paulo Roberto Elian dos (Org.). Manual para gestão de documentos e arquivos de laboratórios das ciências biomédicas. Rio de Janeiro: Casa de Oswaldo Cruz; Faperj. DVDROM. 2011.

SANTOS, Paulo Roberto Elian dos. Arquivística no laboratório: história, teoria e métodos de uma disciplina. Rio de Janeiro: Associação dos Arquivistas Brasileiros; Faperj. 2010. 
SANTOS, Paulo Roberto Elian dos; PINTO, José Mauro da Conceição; SANTOS, Cleber Belmiro dos.

Arquivologia nos laboratórios das ciências biomédicas: os métodos e as práticas de pesquisadores e arquivistas. In: Oliveira, Lucia Maria Velloso de; Silva, Maria Celina Soares de Mello e (Org.). Políticas de aquisição e preservação de acervos em universidades e instituições de pesquisa. Rio de Janeiro: Museu de Astronomia e Ciências Afins. p.161-177. 2012.

SILVA, Maria Celina Soares de Mello e (Org.). Glossário de espécie e tipos documentais em arquivos de laboratórios. Rio de Janeiro: Museu de Astronomia e Ciências Afins. 2014.
SILVA, Maria Celina Soares de Mello e; BARBOZA, Christina Helena (Org.). Acervos de ciência e tecnologia no Brasil: preservação, história e divulgação. Rio de Janeiro: Museu de Astronomia e Ciências Afins. 2012.

SILVA, Maria Celina Soares de Mello e; SANTOS, Paulo Roberto Elian dos (Org.). Arquivos pessoais: história, preservação e memória da ciência. Rio de Janeiro: Associação dos Arquivistas Brasileiros; Faperj. 2012.

\section{$\rightarrow \rightarrow \rightarrow<<<$}




\section{E R R A T A}

Na nota de pesquisa "Documentos de arquivo produzidos pela atividade científica: uma análise dos cadernos de laboratório do Instituto Oswaldo Cruz" (http://dx.doi.org/10.1590/ S0104-59702019000300016), publicada no volume 26, número 3, jul.-set. 2019:

- Na página 1013, onde se lia "Recebido em 22 maio 2018. Aprovado em 24 abr. 2018.",

- leia-se "Recebido em 24 abr. 2018. Aprovado em 22 maio 2018.".

- Na página 1019, na Figura 1, onde se lia:

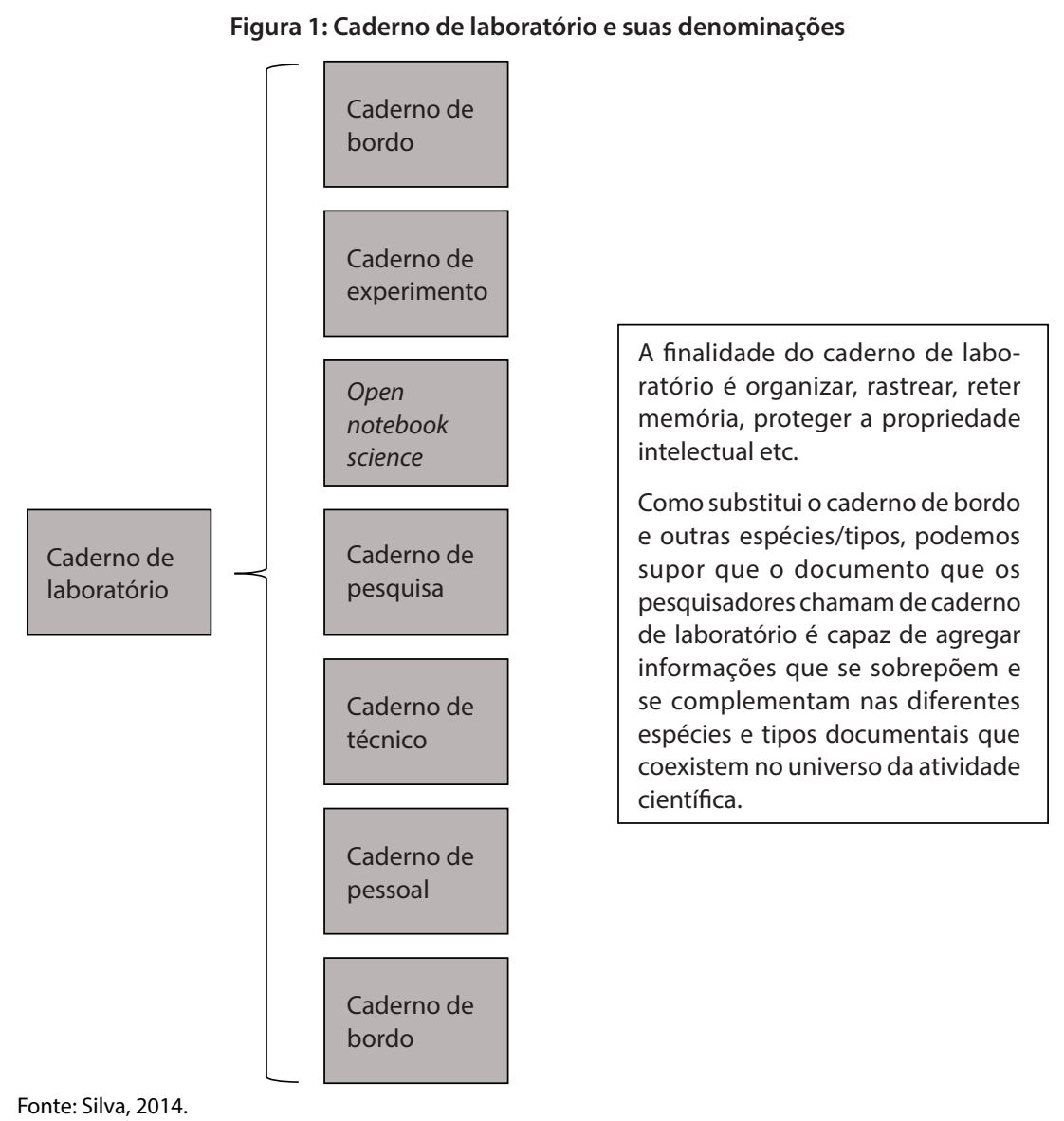


- leia-se:

Figura 1: Caderno de laboratório e suas denominações

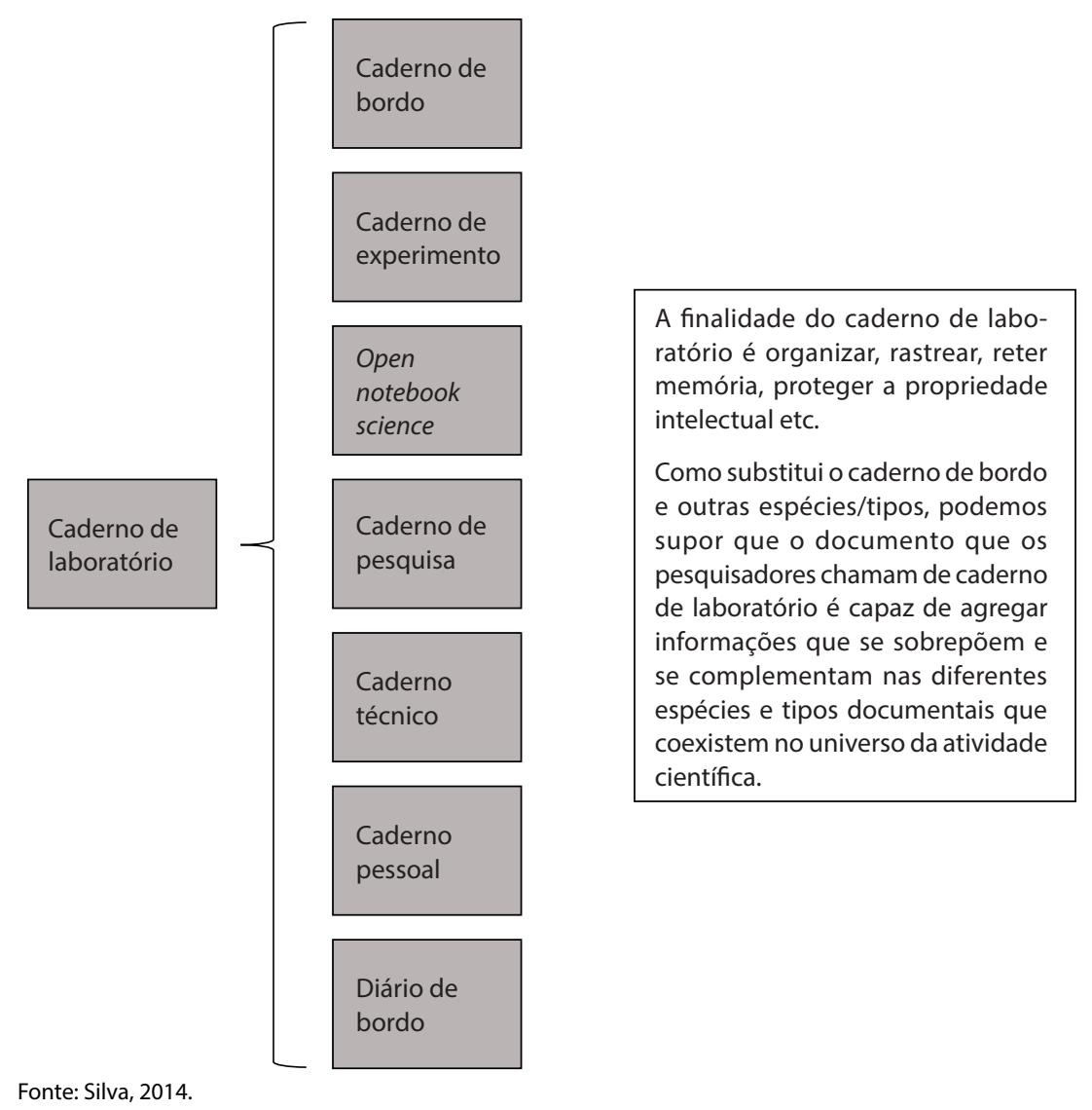

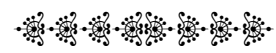

